\title{
Juego latinoamericano, educación física, curriculum y formación integral
}

Eloy Altuve Mejía ${ }^{2}$

eloyaltuve@hotmail.com

Artículo recibido en octubre de 2018 y aprobado en diciembre de 2018.

\section{Resumen}

El propósito del trabajo es demostrar la existencia de prácticas lúdicas latinoamericanas que desarrollan la dimensión física del cuerpo y presentar elementos de una propuesta para su incorporación al curriculum de educación física. Se realiza el levantamiento de una muestra de juegos, explicando su realización y determina el movimiento ejecutado en cada uno, con su denominación común y técnica. Contrastar contenidos y objetivos del curriculum con el movimiento ejecutado, permitió establecer cuáles se pueden desarrollar parcial y/o totalmente en un grado de educación básica y dos años de bachillerato. Finalmente, se demuestra que con el juego latinoamericano, la educación física se alimenta curricularmente y alimenta el curriculum de las demás áreas contribuyendo con la formación integral.

Palabras clave: Juego indígena, juego mestizo, juego latinoamericano, educación física, curriculum, formación integral

\section{Abstract}

The purpose of the work is to demonstrate the existence of Latin

2 Profesor de las cátedras Sociología del Deporte, Prácticas Profesionales y Seminarios de Investigación Educativa, en la Licenciatura de Educación-Educación Física, Deporte y Recreación, de la Facultad de Humanidades y Educación. Fundador y Coordinador del Área de Investigación Educación Física, Deporte y Recreación en el Centro Experimental de Estudios Latinoamericanos Dr. "Gastón Parra Luzardo". Universidad del Zulia, Maracaibo-Venezuela. Actualmente es Coordinador del equipo de investigación de Venezuela y Coinvestigador en el proyecto "Estudio Semántico, Praxiológico y Pedagógico de los contenidos curriculares de los programas oficiales de la Educación Física Escolar en Iberoamérica", de la Universidad de Las Palmas de Gran Canaria, Departamento de Educación Física-Grupo de Investigación en Praxiología Motriz, Entrenamiento Deportivo, Didáctica de las Situaciones Motrices y Salud (GIPEDS) y Asociación Científico Cultural en Actividad Física y Deportes (ACCAFIDE.) 
American play practices that develop the physical dimension of the body and present elements of a proposal for its incorporation into the physical education curriculum. A sample of games is made, explaining its realization and determining the movement executed in each, with its common denomination and technique. Contrasting contents and objectives of the curriculum with the executed movement, allowed to establish which can be partially and / or fully developed in a basic education degree and two years of high school. Finally, it is demonstrated that with the Latin American game, physical education is fed curricularly and feeds the curriculum of the other areas contributing to the integral formation.

Keywords: Indigenous game, mestizo game, Latin American game, physical education, curriculum, integral formation

\section{Introducción ${ }^{3}$}

La construcción colectiva de una educación física (en adelante EF) alternativa parte de considerar lo siguiente:

- La razón y el cuerpo son elementos integrados-complementarios.

- En la escuela, la realización del hombre en su entorno tiene completa propiedad, se trabaja por la recuperación de la corporeidad como condición para una mejora en el aprendizaje y la socialización, simultáneamente con el cultivo de la dignidad.

- La práctica del ejercicio físico amplía la dimensión psico-afectiva.

Apostamos por una EF basada en la formación, organización, placer, solidaridad, etc. que contribuya a la recuperación de la conciencia socio-histórica individual y colectiva dándole vigencia a lo que ha sido nuestra experiencia corporal lúdica ancestral y milenaria lúdica: juego latinoamericano (indígena y mestizo o "tradicional" o "de la calle" o "popular").

3 Expreso mi profundo agradecimiento a mi amigo y colega en el Departamento de Educación Física de la Universidad del Zulia, Profesor Angel Zabaleta, así como a su hija Raizha Abbir Zabaleta Hasboun, quienes desde Maracaibo-Venezuela, me hicieron llegar materiales indispensables para realizar este trabajo. 
Teniendo como referencia las reflexiones anteriores, el propósito de este trabajo es demostrar la existencia de prácticas lúdicas latinoamericanas que desarrollan amplia y profundamente la dimensión física del cuerpo y presentar elementos de una propuesta para su incorporación al curriculum de EF en un proceso único e indivisible de contribución con la formación integral. Particularmente, se evidencia que en la realización del juego latinoamericano se ejecutan ejercicios de distinta naturaleza y de diferente grado de dificultad, cultivándose capacidades, destrezas y habilidades diversas, que posibilitan o permiten el desarrollo parcial y/o total de los contenidos de los programas de EF y simultáneamente se alimenta el curriculum de otras áreas.

\section{Juego indígena}

En la época que va entre el Medioevo y el Renacimiento, de la cultura física en los siglos XVIII y XIX,

La condena de la Iglesia pesó por siglos y el hombre europeo vivió constreñido al abandono físico más absoluto. Durante siglos, los pueblos continentales trataron en lo posible de suponer que el hombre carecía de cuerpo. Y como una de las buenas cualidades de éste consiste en que cuando está sano parece ausente, no se le nota, al punto de que se diría que no existe; el hombre moderno llegó a tenerlo en cuenta sólo cuando tenía dolor. Para facilitar el escamoteo de nuestra corporalidad, se lo tapó. En el siglo $\mathrm{XVIII}$, hasta el cabello es cubierto con una peluca (Vidart, 1986, p. 290).

Por eso, a fines del siglo XVI en Europa y, muy especialmente en España, lo lúdico se centra en la caballería y en algunos otros pasatiempos y diversiones de la nobleza, existiendo también los llamados "juegos de manos o juegos de villanos", reservados a los pobladores de las aldeas. En cambio, en América, en la vida cotidiana indígena el juego era una constante, siempre estaba presente. Las comunidades indígenas tenían y tienen una extensa e intensa práctica lúdica ${ }^{4}$, resumen una experiencia

4 Se dispone de un registro de 27 juegos indígenas previos a la conquista europea, aplicando la metodología de participantes, material, duración, descripción y significado (Altuve, 1997). 
milenaria en materia de juegos. Podemos afirmar -con toda propiedadque:

1) Antes de 1492, existían al menos 10 formas de jugar a la pelota: palin mapuche y pillmatum mapuche-tehuelche en Chile y Argentina; inao en Chile; la othomaca en Venezuela; batos taíno en Puerto Rico, Haití, Jamaica, Islas Bahamas, Cuba y Santo Domingo; tlachtli azteca y poktat-pok maya en México, Guatemala, Belice y Honduras; la guaycurúe en Bolivia, Paraguay y Argentina; gomáhcari tarahumara en México; la del Bajo Putumayo-Colombia; y la de los huitotos, quienes vivían en la región comprendida entre el río Mayo, al suroeste de Colombia, y el río Chota, al norte de Ecuador. 2) Los juegos de pelota de goma capaz de botar y de movimiento vivo, son patrimonio de exclusivo origen americano. Las plantas que producen caucho, goma natural, de mascar o chicle, pertenecen a la flora americana, con la excepción de la arábiga producida en la Península Arábiga. Lo relativo a la goma vegetal fue conocido por los europeos en América. Antes de 1492, en Europa las pelotas eran vejigas de animales llenas de aire y cubiertas con cuero, pelotas de paja e, incluso, de madera. 3) Hace, por lo menos, 3.500 años, existían en América juegos con pelota de goma entre los llamados olmecas arqueológicos ("hombres o habitantes del país de hule"), en el Golfo de México. Entre los aztecas y mayas constituía un espectáculo de contemplación masiva y uno de los aspectos más importantes de su cultura; los europeos, que tenían más de mil años de haber eliminado los juegos olímpicos, quedaron deslumbrados del tamaño del campo de juego, de la cantidad de personas y de la destreza de los jugadores. 4) Existían otros juegos como lucha, golpes, carreras, tiro con arco y flecha, boleadoras, etc.

El juego indígena demanda una gran exigencia física, es complejo en cuanto a su organización y desarrollo, constituye un espectáculo de concurrencia masiva, tiene mucha importancia social y significados diversos. Integra armónicamente diferentes aspectos de la vida social. Comprende la dimensión religiosa, ritual, sirve para la preparación física, es un medio de recreación e incluso, se utiliza en algunas oportunidades para decidir asuntos complejos de distinta naturaleza social; constituye un espacio regular, ordinario, de cohesión social. Esto puede ilustrarse con el palín mapuche de Chile y Argentina (Altuve, 1997): 
1) Participantes: Dos equipos de 50 jugadores cada uno. Las mujeres eran excelentes jugadoras. 2) Material: Un terreno rectangular más largo que ancho, alcanzando hasta una proporción de 20:1 y extensión de $1.600 \mathrm{~m}$. de largo y $80 \mathrm{~m}$. de ancho; en el centro hay un hoyo donde se mete la bola antes de comenzar, mide $30 \mathrm{~cm}$. de diámetro y $15 \mathrm{~cm}$. de profundidad; una bola de piedra, madera u ovillo de lana muy apretado y cubierta de cuero fresco, de 3 a $5 \mathrm{~cm}$. de diámetro y de 45 a 60 gramos de peso; un bastón de madera con una leve curvatura en el extremo distal para golpear la bola, mide 1,051,22 m. y pesa de 400-1.050 gramos. 3) Duración: Variable, podía durar varios días. 4) Descripción: Delimitado el campo de juego y ubicados en el terreno los jugadores con sus bastones, se ordenan en dos hileras de tal manera que cada uno tenga delante su contrario, en una especie de marcación hombre a hombre. Los jugadores se ponen en el centro y, al dar el árbitro la señal, inician el encuentro tratando de sacar la pelota del hoyo para pasársela a sus compañeros. El objetivo es enviar la bola a la parte final del terreno del equipo contrario o meta, anotándose un punto cada vez que se logra (es descontable, si va perdiendo se le resta al que va ganando). El ganador será aquel equipo que obtenga 4 puntos de ventaja. 5) Significado: Tenía una profunda y diversa significación: a) Una comunidad invitaba a otra para agasajarla, jugar formaba parte de una celebración masiva con danzas, música, banquetes y discursos. b) La preparación, desarrollo y predecir el resultado, se asociaba con prácticas rituales, relacionaba a la comunidad con sus dioses, constituía un momento colectivo de compartir, reforzar su forma de entender y explicar el mundo. c) Era un medio que servía para decidir importantes asuntos políticos, militares, etc., donde existía discrepancia. La comunidad del equipo vencedor adquiría el derecho de imponer su decisión. d) Tenía un gran valor social, al punto de que el buen jugador se encontraba -en la escala social- en el mismo nivel que el buen guerrero. 6) Facilitaba la formación integral porque: a) Exigía una gran preparación física, semejante a la preparación militar; los movimientos del juego ayudaban para la guerra. b) Era un medio recreativo: competencias internas; de preparación para un partido importante; amistoso con pequeñas apuestas. c) Era escenario de intensa interacción social: participaban jugadores especializados, mujeres y se hacían elevadas apuestas; toda la comunidad participaba, bien sea como jugadores, espectadores y árbitros. 
El juego, como acción colectiva, ocupaba un lugar central en la organización económica, social y cultural de las comunidades, era una forma de combinar un uso programado y regulado del "tiempo libre" con las prácticas productivas. Esto se evidencia en la pelota othomaca de Venezuela, era una práctica corporal ordinaria, regular, un ingrediente fundamental en la cotidianidad, enmarcada en el conjunto de actividades (división del trabajo, producción y consumo de bienes, necesidades fisiológicas, afectivas, etc.) realizadas diariamente, formaba parte de una disposición de vida donde se establecía una relación armónica del individuo con su cuerpo, con lo(a)s otro(a)s y con la naturaleza:

1) Participantes: Inicialmente 12 hombres por equipo, luego, cuando ingresan las mujeres en similar cantidad son 24 jugadores por bando. 2) Material: Terreno que permite la colocación de un equipo frente a otro, el radio de acción de juego, era -probablemente- como mínimo 1.100 metros cuadrados. Pelota de caucho y palas de madera de $63 \mathrm{~cm}$. de largo y redonda en un extremo con $15 \mathrm{~cm}$. de ancho. 3) Duración: Alrededor de 8 horas, las mujeres jugaban unas 4 horas. 4) Descripción: Ubicados los equipos de hombres, se inicia el juego con el saque por parte de uno y el rechazo del otro, sin utilizar las manos y las piernas para golpear la pelota. Sacar, rechazar, elevar, mantener en el aire, trasladar la pelota de un equipo a otro con la cabeza, hombros, codos, rodillas, nalgas y espalda, constituyen la esencia del juego. Cuando se incorporan las mujeres, al mediodía, golpean la pelota con las palas. Dejar tocar la pelota el suelo o golpearla con las partes prohibidas del cuerpo, son puntos para el equipo contrario. Gana el equipo que acumula la mayor cantidad de puntos. 5) Significado: La vida othomaca todos los días comprendía: a) Levantarse en la madrugada a llorar por los muertos hasta amanecer, luego reina la alegría que se prolonga hasta la noche. b) Inmediatamente viene la división del trabajo: pescar y cazar -un grupo de hombres- y las mujeres a tejer. c) Otros hombres juegan pelota y las mujeres se incorporan a jugar al mediodía. d) Nadar, hacer las necesidades fisiológicas, bailar, cantar, entregarse al amor y dormir (Gumilla, 1968). El juego de pelota en la cotidianidad era un elemento fundamental de la combinación uso programado y regulado del "tiempo libre" y de las prácticas productivas, que garantizaba una saludable conformación física individual-colectiva, acorde con las exigencias de fuerza, resistencia y destreza propias de las labores necesarias para la 
reproducción de la vida material; al mismo tiempo que una socialización permanente entre los distintos miembros de la comunidad, mediante la cual ésta reforzaba sus valores compartidos. Están presentes elementos de carácter ritual: "el anciano que sirve de árbitro y recibe de los jugadores hachas, cuchillos y demás objetos destinados a los vencedores, 'lleva como insignia un trozo de piel de jaguar, emblema del animal totémico consagrado,... a la luna' " (Altuve, 1997, p. 76-77). 6) Facilitaba la formación integral porque era: a) Un elemento clave para el "uso del tiempo libre", recreación y entretenimiento masivamente: toda la comunidad participaba, los hombres se turnaban en las funciones productivas (era rotativo cazar y pesca-jugar) y "la participación de la mujer consideraba sus funciones sociales y su constitución biológica, se incorporaba al mediodía y utilizaba la pala para golpear la pelota. El resto de la comunidad, que no iba a pescar o cazar -a buscar la comidaparticipaban como jugadores, espectadores, árbitros y apostando" (Altuve, 1997, p. 75). b) Muy exigente "en términos de condiciones psicofísicas, implica desarrollar la resistencia, fuerza, agilidad, coordinación, trabajo en equipo, inteligencia, capacidad de improvisación, Y... extremadamente compleja en su organización, funcionamiento, normas, participantes, materiales y duración" (Altuve, 1997, p. 76).

Otro importante juego de pelota era el tlachtli azteca y pokyah o pot-tat-pok maya de México, Guatemala, Belice y Honduras, complejo y de gran significación social:

1) Participantes: Dos equipos de hombres: dos contra dos, tres contra tres, etc. El número dependía del tamaño del campo de juego. 2) Material: El campo de juego era una especie de cancha con forma de $\mathrm{I}$, de $\mathrm{H}$ mayúscula acostada o doble $\mathrm{T}$; las dimensiones variaban, existían algunos muy grandes como el de Chichén Itzá, en la Península de Yucatán, con $146 \mathrm{~m}$. de largo y $64 \mathrm{~m}$. de ancho, y el de Tingambato, en el estado de Michoacán (México), con 40m. de largo por 13,5m. de ancho. Estaba constituido por tres patios:

Dos laterales para los espectadores...eran dos muros blanqueados, paredes de piedra con gradas de asiento, medían hasta $12 \mathrm{~m}$. y $15 \mathrm{~m}$. de largo y tenían 2,5m. de altura en adelante. En el centro de cada muro, en la parte superior cerca del borde de la pared, se insertaba verticalmente -a 
diferencia de la posición horizontal del aro de baloncestoun anillo de piedra o de madera...La distancia del anillo al suelo era como mínimo de 2,5m., llegando a alcanzar en algunos casos hasta $8 \mathrm{~m}$. de separación...Uno central para los jugadores...tenía: a) De ancho la distancia que separaba los patios laterales, variable entre $3 \mathrm{~m}$. y $30 \mathrm{~m}$.. b) De largo entre $7 \mathrm{~m}$. y $40 \mathrm{~m} . . \mathrm{c}$ ) En el centro una línea que delimitaba el campo de juego de los equipos...d) Centrados los anillos, coincidiendo con el centro de los patios laterales (Altuve, 1997, p. 80-81).

3) Duración: Como era muy difícil introducir la pelota en los anillos, sentido esencial del juego, los partidos se extendían por horas y hasta días completos. 4) Descripción:

Conformados los equipos, separados por la raya del medio en el patio central e iniciado el juego, era obligación de los jugadores mantener la pelota en movimiento, en el aire, utilizando únicamente para golpearla las nalgas, codos, caderas, muslos, rodillas, siendo prohibir usar las manos y los pies ...El objetivo fundamental era hacer pasar la pelota por cualquiera de los anillos; cuando alguien lo lograba se constituía en el ganador absoluto del juego y culminaba el encuentro...Como era muy difícil meter la pelota en los anillos, tenían un sistema de puntuación o rayas, de tal manera que al no lograr encestar ninguno de los equipos, el ganador seía aquel que incurriera en menos faltas y acumulara más rayas o puntos. Se incurría en una falta y era punto para el contrario, al golpear la pelota con las partes del cuerpo no permitidas o dejarla caer al suelo en su zona (Altuve, 1997, p. 82-83).

5) Significado: Socialmente, es una de las dimensiones más importantes de las culturas mesoamericanas, debido a: a) Su carácter masivo, popular. b) Su valor transcendía a lo político y lo económico. Era tal la importancia del juego, que en oportunidades hasta el tributo de pueblos sometidos a los aztecas podía pagarse en pelotas. c) Que la naturaleza de los jugadores, el incentivo y el tipo de participación estaba vinculado al nivel social de los participantes. El entretenimiento, 
la diversión y las apuestas comprendían por igual a jugadores y espectadores. d) Que servía para registrar acontecimientos muy significativos. e) Que tenía un gran valor social. Ser un excelente jugador lo dotaba de privilegios y prestigio. f) Su dimensión religiosa, estaba estrechamente ligado, articulado íntimamente al sistema de creencias, de formas de explicar el mundo; era un espacio social, una oportunidad colectiva para reforzar las creencias en fuerzas superiores que lo regían todo. 6) Facilitaba la formación integral porque: a) La exigencia corporal es muy amplia y extremadamente fuerte: resistencia, desttreza, fuerza, agilidad, coordinación, puntería, inteligencia, táctica y estrategia de juego, etc.. b) Era un medio de recreación, pasatiempo, entretenimiento y un escenario de intensa interacción social.

\section{Juego mestizo}

Cuando invaden América (trasladando su concepción sobre el cuerpo) los europeos se dan cuenta que esa profunda imbricación, integración del juego con el sentido de pertenencia a la comunidad, reforzaba, expresaba, reproducía y alimentaba -constantemente- los fundamentos de funcionamiento de la sociedad aborigen. $Y$ por eso lo prohibieron; al prohibir el juego, por una parte, estaban negando la concepción del mundo y de la vida indígena y afirmando la suya como dominante y superior, y por la otra, convierten el tiempo de juego comunitario en tiempo de trabajo expropiable en su beneficio, como clase dominante.

En general, la cultura del conquistador europeo no pudo aniquilar totalmente la cultura aborigen; también incorporó, como requisito del proceso de colonización en condición de subordinación, la cultura africana. Particularmente, en lo lúdico se articularon y mezclaron prácticas corporales, elementos de juegos aborígenes, europeos y africanos, con predominio del elemento europeo, de manera entrelazada, contradictoria, superpuestos, opuestos, complementarios y, en definitiva, indiferenciados. Resultando como producto un híbrido lúdico, una creación lúdica de América Latina: el juego mestizo latinoamericano. Veamos: 
Cuadro N.1. Muestra de juegos españoles del siglo XVI transformados en juegos mestizos con su denominación en los países $\left(^{\star}\right)$.

\begin{tabular}{|c|c|c|c|c|c|}
\hline \multirow[t]{3}{*}{ PAís } & \multicolumn{5}{|c|}{ JUEGOS ESPAÑOLES } \\
\hline & $\begin{array}{l}\text { Pásome acá con } \\
\text { Gil de Carmona; } \\
\text { A pie coxcoja }\end{array}$ & $\begin{array}{l}\text { ¿Está acá tu } \\
\text { madre?; Esotro } \\
\text { lo sabe }\end{array}$ & $\begin{array}{l}\text { Contrabandistas y } \\
\text { carabineros; Moros } \\
\text { y cristianos }\end{array}$ & $\begin{array}{l}\text { Recotín, recotan, } \\
\text { vuelve la mano } \\
\text { atrás; Decodín, } \\
\text { decodón }\end{array}$ & $\begin{array}{l}\text { Hebrita de oro } \\
\text { traigo, quebrán- } \\
\text { dose me viene }\end{array}$ \\
\hline & $\begin{array}{l}\text { Gambeta; Lu- } \\
\text { che; Tejo; Ra- } \\
\text { yuela; Tilín; Tun- } \\
\text { cuna }\end{array}$ & El huevito & Vigilante y ladrón & $\begin{array}{l}\text { Alillén, alillán; } \\
\text { Aserrín, aserrán }\end{array}$ & $\begin{array}{l}\text { Hilo de oro; Hilo } \\
\text { de oro y plata; } \\
\text { Las hijas del rey } \\
\text { moro }\end{array}$ \\
\hline Argentina & $\begin{array}{l}\text { Luche; Lucho; } \\
\text { Tejo; Mariola; } \\
\text { Coxcojilla; Raina } \\
\text { mora; Inferná- } \\
\text { culo }\end{array}$ & $\begin{array}{l}\text { El vendedor de } \\
\text { huevos; Com- } \\
\text { pra huevos; Las } \\
4 \text { esquinas }\end{array}$ & $\begin{array}{l}\text { Paco ladrón; Ladro- } \\
\text { nes y policías }\end{array}$ & Aserrín, aserrán & $\begin{array}{l}\text { Vamos jugando } \\
\text { al hilo de oro; Al } \\
\text { hilito de oro; El } \\
\text { hilo de oro }\end{array}$ \\
\hline Chile & $\begin{array}{l}\text { Rayuela; La gru- } \\
\text { lla; Pisé; Des- } \\
\text { canso }\end{array}$ & $\begin{array}{l}\text { El cuartillo de } \\
\text { larepita }\end{array}$ & $\begin{array}{l}\text { Policía y ladrón } \\
\text { librado; Jueretay; } \\
\text { Libertad, guerra; } \\
\text { Guataco por las } \\
\text { orejas; Ladrones y } \\
\text { policías }\end{array}$ & Aserrín, aserrán & Hilito de oro \\
\hline Venezuela & Mundo; Rayuela & $\begin{array}{l}\text { Los huevos; Los } \\
\text { huevitos; Las } 4 \\
\text { esquinas; Pedir } \\
\text { candela }\end{array}$ & $\star \star$ & $\begin{array}{l}\text { Los maderos de } \\
\text { San Juán }\end{array}$ & $\begin{array}{l}\text { Alelito, alelito } \\
\text { de oro; Hebrita } \\
\text { de oro; Hilo de } \\
\text { oro, hilo de plata }\end{array}$ \\
\hline Perú & $\begin{array}{l}\text { Rayuela; } \\
\text { Teja }\end{array}$ & $\begin{array}{l}\text { ¿Está acá tú } \\
\text { madre? }\end{array}$ & $\star *$ & $\begin{array}{l}\text { Los maderos de } \\
\text { San Juán }\end{array}$ & Hilo de oro \\
\hline Uruguay & Tejo; Pije & ** & ** & $\begin{array}{l}\text { Los maderos de } \\
\text { San Juán }\end{array}$ & Hilitos de oro \\
\hline México & Rayuela; Ficha & $\begin{array}{l}\text { Las cuatro es- } \\
\text { quinas }\end{array}$ & $\begin{array}{l}\text { Moros y cristianos; } \\
\text { Perros y venados; } \\
\text { Policías y ladrones }\end{array}$ & $\begin{array}{l}\text { Rocotín; Aserrín, } \\
\text { aserrán }\end{array}$ & $\begin{array}{l}\text { Hilitos, hilitos } \\
\text { de oro }\end{array}$ \\
\hline
\end{tabular}

(*) La muestra registrada también existe en Bolivia, Paraguay y Guatemala. Sin duda, existe una práctica lúdica mestiza, con especificidad en los países, pero, en esencia son los mismos. Ratificado en talleres y encuentros donde hemos participado con personas de diferente procedencia, nos entendemos rápida y perfectamente bien, nos identificamos con una práctica lúdica común y diferenciada en detalles.

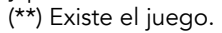

Fuente: Elaboración propia basada en Altuve, 1995; Altuve, 2000; Becerra, 2018; Hernández, 1876; López, 1992; Ministerio del Deporte, 2018; Moreno, 1974; Parra, 2018; Plath, 1986; Rodríguez, 1932. 
Cuadro N.2. Versiones nacionales de una muestra de juegos mestizos latinoamericanos.

\begin{tabular}{|c|c|}
\hline Ecuador & Venezuela $\left({ }^{\star}\right)$ \\
\hline $\begin{array}{l}\text { RAYUELA: Existen diferentes formas de rayuela (avión, } \\
\text { gato, días de la semana, etc.), pero, básicamente } \\
\text { consiste en saltar con un solo pie y sin pisar las rayas } \\
\text { divisorias de los cajones con los cuales se ha dibujado } \\
\text { la gura. }\end{array}$ & $\begin{array}{l}\text { PISÉ, DESCANSO. Participantes: Niños y niñas. Material: Tiza, } \\
\text { objetos pequeños planos como piedras, pedazos de vidrio, etc.. } \\
\text { Duración: llimitada. Una ronda finaliza cuando un participante se } \\
\text { apodera del mayor número de casillas. Descripción: Primera fase: } \\
\text { Se hace la figura del pisé en el suelo: caracol, avión...etc.. Por } \\
\text { orden, establecido por sorteo, cada jugador lanza su piedra al } \\
\text { primer cuadro; debe saltar sin tocarlo, recorriendo con un solo pie } \\
\text { el resto del pisé, se devuelve, toma la piedra y salta nuevamente. } \\
\text { Luego, pasa por todos los cuadros hasta el momento de incurrir } \\
\text { en una falla, cuando le corresponde el turno al contrario. Se con- } \\
\text { sideran errores tirar la piedra y caer en una línea del pisé o en el } \\
\text { cuadro que no le corresponda, caminar. Segunda fase: Idéntica a } \\
\text { la anterior, se realiza con los ojos vendados, caminando. Aquel que } \\
\text { logra recorrer exitosamente todo el pisé se hace propietario del } \\
\text { cuadro donde lanzó la piedrita, impidiendo que los otros partici- } \\
\text { pantes puedan tocarlo debiendo saltarlo. El ganador es el jugador } \\
\text { dueño de más cuadros. }\end{array}$ \\
\hline $\begin{array}{l}\text { PERROS Y VENADOS (POLICÍAS Y LADRONES): Parti- } \\
\text { cipantes: Dos grupos con varios miembros. Duración: } \\
\text { Depende del número de participantes. Proceso: El } \\
\text { equipo de los guardias trata de coger a los miembros } \\
\text { del grupo de los ladrones y meterlos en la cárcel. Los } \\
\text { ladrones pueden ser salvados por sus compañeros si } \\
\text { son tocados en la cárcel. El juego termina cuando to- } \\
\text { dos los ladrones están en la cárcel. }\end{array}$ & $\begin{array}{l}\text { LIBERTAD, GUERRA (POLICIAS Y LADRONES). Participantes: } \\
\text { Niñas y niños. Dos equipos de } 3-6 \text { integrantes. Material: Espa- } \\
\text { cio, bases o puestos que pueden ser matas o árboles, pilares de } \\
\text { cemento, piedras, círculos dibujados en tierra, etc. Duración: } \\
\text { llimitada. Descripción: Ubicándose en sitios diferentes llamados } \\
\text { bases, los integrantes de un equipo van saliendo progresivamente } \\
\text { mientras el grupo contrario los persigue para tocarlos. Al ser toca- } \\
\underline{\text { do algún jugador queda paralizado, y para moverse debe pasar un }} \\
\text { compañero y darle tres palmadas diciendo } 1,2,3 \text { libertad, quedan- } \\
\text { do libre. También podía ser liberado cuando los compañeros for- } \\
\text { maban una cadena desde su base tocándolo; el equipo contrario } \\
\text { tiene derecho a romper la cadena. De mutuo acuerdo, los grupos } \\
\text { se cambian de rol pasando de perseguidos a perseguidores y vice- } \\
\text { versa. A los bandos se les denominaba ejército y marina, policías } \\
\text { y ladrones. }\end{array}$ \\
\hline $\begin{array}{l}\text { LAS CUATRO ESQUINAS... Participantes: Cinco. Du- } \\
\text { ración: Depende de los participantes Proceso: Cada } \\
\text { esquina es ocupada por un jugador y un quinto se } \\
\text { queda. Este pregunta a uno de los jugadores ¿Qué } \\
\text { hay en la casita que alquilar?, quien responde A otro } \\
\text { lugar que esta está ocupa. En ese momento los demás } \\
\text { jugadores intercambian sus lugares rápidamente. Si el } \\
\text { jugador que se queda ocupa uno de los lugares vacíos, } \\
\text { se lo queda y el que no tiene esquina pasa a quedarse. }\end{array}$ & $\begin{array}{l}\text { EL CUARTILLO DE LAREPITA. Participantes: Niños y niñas. Dura- } \\
\text { ción: llimitada. Material: Espacio, bases o puestos. Descripción: } \\
\text { Se ubican las bases, existiendo una menos que el número de ju- } \\
\text { gadores. A la voz de ya, corren a posesionarse de su base, que- } \\
\text { dando uno por fuera, quien se la queda y debe pedir } \underline{\underline{\text { el cuartillo }}} \\
\underline{\text { de larepita. Se dirige a cada uno y le dice } \underline{\text { dame el cuartillo de }}} \\
\underline{\text { larepita, quien responde que no es aquí que es allá, yo no lo ten- }} \\
\text { go, lo tiene fulano (nombre de otro jugador). En ese instante los } \\
\text { participantes se cambian de puesto y el quedao aprovecha para } \\
\text { intentar apoderarse de alguna base y hacer quedar a otro. }\end{array}$ \\
\hline
\end{tabular}




\begin{tabular}{|c|c|}
\hline EL GATO Y EL RATÓN: Ronda infantil & $\begin{array}{l}\text { EL GATO Y EL RATÓN. Participantes: Niños y niñas. Material: } \\
\text { Espacio. Duración: Indefinida. Descripción: Se sortea quien va a } \\
\text { hacer las veces de gato y los demás forman un círculo. El gato ca- } \\
\text { mina a su alrededor tocando a alguno y estableciendo la siguiente } \\
\text { conversación: Gato: tun, tun; Tocado: ¿quién es?; Gato: Tocado: } \\
\text { ¿a quién busca?; Gato: Al ratón; Tocado: Está durmiendo, no está. } \\
\text { Al responder el jugador tocado y salir corriendo fuera del círculo } \\
\text { se convierte en ratón y el gato lo persigue evitando su regreso } \\
\text { al círculo donde estaría a salvo. Si logra atrapar al ratón, éste se } \\
\text { convierte en gato, y el antiguo gato entra al círculo. Y así sucesi- } \\
\text { vamente se repite la ronda. }\end{array}$ \\
\hline $\begin{array}{l}\text { ASERRÍN, ASERRÁN: Ronda infantil. ROCOTÍN: El niño } \\
\text { se coloca boca abajo sobre las piernas de una persona, } \\
\text { ésta al son de una canción y moviendo el codo sobre } \\
\text { su espalda, le pide que adivine cuantos dedos hay en- } \\
\text { cima, si el niño adivina, gana. }\end{array}$ & ASERRÍN, ASERRÁN: Ronda infantil \\
\hline HILITOS, HILITOS DE ORO: Ronda infantil & HILITOS, HILITOS DE ORO: Ronda infantil \\
\hline $\begin{array}{l}\text { COMETA: Consiste en hacer volarlas y por eso, la mejor } \\
\text { época es cuando corre viento. }\end{array}$ & $\begin{array}{l}\text { VOLANTíN, PETACA, PAPAGALLO, COMETA. Participantes: Casi } \\
\text { siempre niños. Material: Papel, trapo, madera almidón, tijeras, } \\
\text { hojillas, cabuya, anime, pita o hilaza (cabuya), plumas, semillas } \\
\text { de glemón (verdes) y piedras de almagle (rojo) para darle color } \\
\text { al papel, palos de palmera, caña brava o bambú. Amplio terreno } \\
\text { y fuerte viento. Duración: Indefinida. Modalidad: Elevarlo con o } \\
\text { sin hojilla en la cola o rabo. Descripción: Se hacen formas de pa- } \\
\text { pel (cajón, estrella, H...). Luego se moldean y amarran las partes } \\
\text { utilizando los palos y conforma la estructura, que se adhiere al } \\
\text { papel utilizando almidón u otro pegamento, amarrando en la parte } \\
\text { inferior un rabo o cola construido con retazos de tela o papel. El } \\
\text { objetivo es elevarlo y mantenerlo lo más alto posible. Al llevar } \\
\text { hojilla en el rabo se pretende también cortar la cabuya o hilo del } \\
\text { contrario para eliminarlo del juego. }\end{array}$ \\
\hline $\begin{array}{l}\text { CANICAS, BOLAS (bomba, ñoco, pepo y trulo, cule- } \\
\text { bra..Participantes: Varios. Duración: } 30 \text { minutos. Mo- } \\
\text { dalidades: 1) El Bombardero: Se traza un círculo de } \\
\text { unos } 30 \mathrm{~cm} \text {. en el suelo y cada uno de los participantes } \\
\text { coloca igual número de canicas. El objetivo es bombar- } \\
\text { dear -en orden establecido por sorteo-y sacar las bolas } \\
\text { del círculo. Las canicas sacadas pasarán a ser propie- } \\
\text { dad del jugador-lanzador. Se finaliza cuando el círculo } \\
\text { queda vacío. 2) El Círculo: En un círculo se determina } \\
\text { la posición del lanzador y en otro se colocan las cani- } \\
\text { cas. Cada jugador tira una canica para acertar alguna } \\
\text { del círculo, si lo consigue es suya y sigue tirando hasta } \\
\text { fallar, cuando le corresponde lanzar a otro; también se } \\
\text { deciden los turnos de lanzamiento, asignando una tira- } \\
\text { da a cada jugador. 3) El Túnel: Consiste en introducir } \\
\text { la canica desde una distancia determinada a un agujero } \\
\text { o túnel. 4) El triángulo: Semejante a la modalidad de } \\
\text { tribilín, circulo, rayo, rayito, de Venezuela. }\end{array}$ & $\begin{array}{l}\text { METRAS. Participantes: llimitado, generalmente niños, también } \\
\text { jugaban niños y niñas. Material: Metras de fibra de vidrio, parapa- } \\
\text { ras, bolitas de barro, terreno. Duración: llimitada. Modalidad: Tri- } \\
\text { bilin, círculo, rayo, rayito. Descripción: Se hace una figura (óvalo, } \\
\text { triángulo, etc.) colocando las metras. A una distancia de } 15 \text { pasos } \\
\text { se traza una línea recta o raya, hacia donde será lanzada una metra } \\
\text { por jugador; aquel que quede más cerca tiene derecho a lanzar } \\
\text { primero a la figura intentando sacar las metras. Al fallar, los demás } \\
\text { participantes lanzan siguiendo el orden determinado previamen- } \\
\text { te por la mayor cercanía a la raya. Al quedar por lo menos una me- } \\
\text { tra, todo aquel que hubiese sacado metras debe cuidarse porque } \\
\text { si un contrario le pega deberá entregárselas, quedando fuera de } \\
\text { la partida. Esta finaliza al no quedar metras en la figura, bien sea } \\
\text { porque han sido todas sacadas o se han eliminado los adversarios. } \\
\text { El ganador es aquel que logra obtener una cantidad de metras } \\
\text { superior a las que inicialmente aportó o cazó, es decir, se apoderó } \\
\text { o ganó metras de los contrarios. }\end{array}$ \\
\hline
\end{tabular}


TROMPO, CUSHPI. Recurso: Un trompo y piola. Participantes: $3-5$ y más jugadores. Duración: 30 minutos. Material: Trompo, peón o peonza, de madera con forma de una fruta de pera. Proceso: Se marca un redondel de unos dos metros de diámetro, para que cada jugador tire el trompo_sobre el centro. "Al mismo tiempo que daba el rejo en el suelo, era tirar la cuerda para llevársele fuera del círculo marcado. Si lo conseguía no pasaba nada, pero el primero que se quedaba dentro, había que dejarle hasta que se parara donde fuese, pues éste era el perdedor. Con la buena intención de poderle dar con el afilado rejo de cada uno y hacerle una cocá que era una buena señal en la madera. Si al recibir uno de estos porrazos se le sacaba del redondel, entonces quedaba libre, por lo que se terminaba el juego, teniendo que empezar nuevamente como a lo primero, que algunas veces solía ocurrir, que el primero que había perdido lo fuera luego en el segundo".

LA CUERDA, LA SOGA. Cuando se juega grupalmente, dos personas sujetan por los extremos una soga y la hacen girar, mientras los demás participantes deben saltarla $\sin$ tropezar. Al jugar individualmente, el participante que salta sostiene la cuerda. A veces se hacen competencias, tales como quién dura más tiempo saltando. Los niños y niñas suelen cantar mientras saltan.
TROMPO. Participantes: llimitado, generalmente niños. Material: Trompo de madera o plástico con la punta de hierro. Duración: llimitada. Descripción: Se hace un círculo con una marca (cruz, piedra o moneda) en el centro. El jugador que lance o pique más lejos de la marca se la queda y coloca su trompo en el centro, los demás jugadores intentan sacarlo del círculo para pasearlo, recorriendo una distancia previamente establecida. Al fallar alguno en el intento de sacar el trompo quedao del círculo o por no tocarlo durante el paseo, coloca su propio trompo, quedándose y se levanta el del contrario. El primero que sea paseado, se penaliza con los clavados o chipolas, acción de amarrar el trompo perdedor y golpearlo con la punta de los demás trompos. El número de chipolas se establece antes de iniciar la partida.
LAS CUERDAS. Participantes: Niñas y niños. Máximo diez, mínimo tres y hasta dos al amarrar la cuerda a algún objeto fuerte. Material: Espacio,_cuerda de mecate, trapo, plástico. Duración: llimitada. Descripción: Se forman dos grupos con 4-5 jugadores. Dos integrantes de cada grupo toman la cuerda por un extremo, moviéndola de derecha a izquierda al nivel o tocando el suelo, mientras los otros dos miembros saltan tratando de mantenerse sin tropezar, sin perder. El ganador será el equipo que logre mantenerse más tiempo saltando sin perder.

STOP, FUSILAO. Participantes: Indefinido, generalmente niños. Material: Pelota de goma, trapo. Duración: Indefinida. Descripción: Se hace una cantidad de huecos enumerados, asignando uno a cada participante. Colocado al frente un jugador trata de meter la pelota en alguno distinto al suyo. Al lograrlo, el señalado se desplaza a buscar la pelota mientras los demás se alejan lo más que pueden, al tenerla grita stop y todos deben pararse e inmediatamente da tres pasos y trata de pegársela al ubicado más cerca. El objetivo es castigar al jugador que cometa tres errores, siendo considerados como tales: fallar al intentar pegarle al contrario y ser blanco fácil del contrario (dejarse pegar). El castigo es ser fusilao: se coloca de espalda y los demás le pegan la pelota tantas veces como fue acordado al inicio del juego.

SIGA AL JEFE. Participantes: Indefinido, niños y niñas. Material: Espacio Duración: Indefinida. Descripción: Se selecciona un jefe, quien realizará gestos, movimientos, voces o cualquier acción que desee, debiendo el resto imitarlo. Cada participante hará las veces de jefe, culminando esa ronda del juego cuando todos lo hayan realizado.

(*) Se dispone del registro de 48 juegos con informantes procedentes, principalmente, de los estados Zulia, Trujillo y Falcón (Altuve, 1992: 64-86).

Fuente: Elaboración propia basada en: Altuve, 1992; Analuiza, Lara y Mendoza, 2017; Becerra, 2011; Martínez, 2018; Ministerio del Deporte, 2010. 


\section{Juego latinoamericano y curriculum de educación física}

Utilizando una muestra de juegos latinoamericanos previamente descritos, se determina el movimiento realizado en cada uno, registrando su denominación común y técnica. Se revisan los contenidos y objetivos simultáneamente con el movimiento, identificándose los que pueden ser desarrollados con los juegos específicos.

\section{Juego mestizo}

Cuadro N.3. Movimiento ejecutado en el juego mestizo (Venezuela) (*).

\begin{tabular}{|c|c|c|}
\hline Juego & $\begin{array}{l}\text { Movimiento ejecutado. } \\
\text { Nombre común }\end{array}$ & $\begin{array}{l}\text { Movimiento ejecutado. } \\
\text { Nombre técnico }\end{array}$ \\
\hline Pisé o descanso. & $\begin{array}{l}\text { - Tomar la piedra con la } \\
\text { mano. } \\
\text { - Tirar la piedra en forma de } \\
\text { bombita. } \\
\text { - Brincar con un solo pie los } \\
\text { cuadros correspondientes. } \\
\text { - Doblarse hacia adelante en } \\
\text { un solo pie para agarrar la } \\
\text { piedra. } \\
\text { - Tirar la piedra "de a } \\
\text { pa'tras". }\end{array}$ & $\begin{array}{l}\text { - Flexión y extensión de dedos. } \\
\text { Brazos extendidos y en } \\
\text { supinación. } \\
\text { - Balanceo del brazo en el plano } \\
\text { sagital. } \\
\text { - Rechazo, saltos o botes } \\
\text { unipodales y bipodales. } \\
\text { - Posición de equilibrio, semi- } \\
\text { flexión y extensión en la } \\
\text { articulación de la rodilla. } \\
\text { - Lanzamientos. }\end{array}$ \\
\hline $\begin{array}{l}\text { Libertad y guerra; } \\
\text { Policía y ladrones. }\end{array}$ & $\begin{array}{l}\text { - Correr. } \\
\text { - Agarrarse y "amarrarse". } \\
\text { - Agarrar un contrario } \\
\text { inmovilizándolo de } \\
\text { cualquier forma. } \\
\text { - Tirarse al suelo y } \\
\text { esconderse. }\end{array}$ & $\begin{array}{l}\text { - Desplazamientos en distintas } \\
\text { direcciones (carreras } \\
\text { intermitentes). } \\
\text { - Flexión y extensión de los } \\
\text { miembros superiores. } \\
\text { - Lanzarse de cúbito-abdominal. } \\
\text { - Fintas, luchar. }\end{array}$ \\
\hline $\begin{array}{l}\text { El cuartillo de } \\
\text { larepita }\end{array}$ & $\begin{array}{l}\text { - Caminar y correr. } \\
\text { - Estirar el brazo. }\end{array}$ & $\begin{array}{l}\text { - Desplazamiento en distintas } \\
\text { direcciones. } \\
\text { - Hiperextensión del brazo. } \\
\text { - Giros del cuerpo. }\end{array}$ \\
\hline
\end{tabular}

(*) Se dispone de la identificación del movimiento ejecutado con su respectiva denominación en 28 juegos (Altuve, 1992: 89-97).

Fuente: Altuve, 1992. 
Cuadro N.4. Contenidos y objetivos de educación física de sexto año de educación básica venezolana, a desarrollar y alcanzar con el juego mestizo $\left(^{(}\right)$.

\begin{tabular}{|c|c|c|}
\hline Contenido y objetivos & Juegos & Actividades del juego \\
\hline $\begin{array}{l}\text { Capacidad aeróbica, Potencia anaeróbica. } \\
\text { 1.2: Trotar en forma continua y uniforme...1.3: } \\
\text { Realizar carreras a intervalos aumentadas } \\
\text { progresivamente de } 4 \times 200 \text { metros...2.1: } \\
\text { Realizar carreras a intervalos aumentadas } \\
\text { progresivamente de } 5 \times 50 \text { a } 7 \times 50 \text { metros...2.2: } \\
\text { Realizar la mayor cantidad de repeticiones en } \\
\text { los ejercicios de circuitos de entrenamiento de } \\
6 \text { estaciones...2.3: Realizar a la mayor velocidad } \\
\text { ejercicios de circuitos de entrenamiento... }\end{array}$ & $\begin{array}{l}\text { Stop-fusilao; Gato y } \\
\text { ratón; Libertad y guerra- } \\
\text { Policía y ladrones; El } \\
\text { cuartillo de larepita. }\end{array}$ & $\begin{array}{l}\text { Formación de ajedrez; } \\
\text { Posición de pie, equilibrio, } \\
\text { lanzamiento a diferentes } \\
\text { lugares; Desplazamientos; } \\
\text { Carreras; Saltos. }\end{array}$ \\
\hline $\begin{array}{l}\text { Flexibilidad } \\
\text { 3.1: Realizar ejercicios de movilidad articular y } \\
\text { elongación muscular...3.3: Realizar ejercicios de } \\
\text { movilidad articular y elongación muscular por } \\
\text { parejas... }\end{array}$ & $\begin{array}{l}\text { Metras, canicas; } \\
\text { Petaca, volantín; Pisé o } \\
\text { descanso. }\end{array}$ & $\begin{array}{l}\text { Flexión y extensión; } \\
\text { Abducción y aducción; } \\
\text { Lanzamiento; Cuclillas; } \\
\text { equilibrio unipodal y bipodal. }\end{array}$ \\
\hline $\begin{array}{l}\text { Fútbol sala o "fútbolito": Marcación hombre a } \\
\text { hombre; Ataque a contra golpe } \\
\text { 5.15: Realizar ejercicios para la práctica de } \\
\text { marcación de hombre y ataque a contragolpe... }\end{array}$ & $\begin{array}{l}\text { Libertad y guerra-Policía } \\
\text { y ladrones. }\end{array}$ & $\begin{array}{l}\text { Desplazamientos rápido } \\
\text { y lento; Finta; Velocidad; } \\
\text { Flexión-extensión; Fuerza- } \\
\text { destreza. }\end{array}$ \\
\hline $\begin{array}{l}\text { Gimnasia artística femenina: Combinación de } \\
\text { ejercicios manos libres } \\
\text { 6.11: Realizar combinaciones de ejercicios a } \\
\text { manos libres: de pie con brazos a los lados, } \\
\text { paradas de manos y rodar de pie...6.12: Realizar } \\
\text { combinaciones de ejercicios a manos libres: } 1 / 2 \\
\text { giro, salto splint, rueda lateral... }\end{array}$ & Siga al jefe. & $\begin{array}{l}\text { Posición de pie; Flexión y } \\
\text { extensión; Giros; Saltos; } \\
\text { Desplazamiento; Pasos; } \\
\text { Equilibrio; Coordinación; } \\
\text { Movimientos rítmicos. }\end{array}$ \\
\hline $\begin{array}{l}\text { Gimnasia artística masculina: Combinación de } \\
\text { ejercicios manos libres } \\
\text { 6.11: Realizar combinaciones de ejercicios a } \\
\text { manos libres: } 1 \text { a } 3 \text { pasos de carrera, rueda } \\
\text { lateral, } 1 / 4 \text { giro, parada de manos pasajera...6.12: } \\
\text { Realizar combinaciones de ejercicios a manos } \\
\text { libres: desde apoyo facial, extendiendo ballesteo } \\
\text { o cuclilla... }\end{array}$ & Siga al jefe. & $\begin{array}{l}\text { Posición sentados y } \\
\text { de cuclillas; Flexión y } \\
\text { extensión; Giros; Saltos; } \\
\text { Desplazamiento; Pasos; } \\
\text { Equilibrio; Coordinación; } \\
\text { Movimientos rítmicos; } \\
\text { Aducción y abducción. }\end{array}$ \\
\hline
\end{tabular}

(*) Se diseñó una propuesta de incorporación de los juegos mestizos al programa completo de sexto año (último de la educación primaria) de la educación básica (séptimo, octavo y noveno grado) (Altuve, 1992: 44-97).

Fuente: Altuve, 1992. 
En la perspectiva de incorporar el juego al curriculum de educación física, profesores de la Facultad de Cultura Física de la Universidad Central del Ecuador, han señalado que:

El juego en las clases de educación física debe ser un proceso que aporte a la formación del educando y facilite el trabajo del docente. En este trabajo se plantea una propuesta de juegos populares en donde se identifica su aporte didáctico y posibles adaptaciones que permitirán un desarrollo más operativo de las clases de educación física (Analuiza, Lara y Mendoza, 2017, p. 79).

Realizan una propuesta con los juegos el palo encebado, trompo (cushpi), la rueda, la rayuela, las bolas o canicas, el elástico y los zancos. Su metodología comprende: ¿Qué es el juego?; Participantes; Objetivo; ¿Cómo se juega?; Acuerdos (reglas del juego); Recursos y el Aporte Didáctico (Analuiza, Lara y Mendoza, 2017). Con el palo encebado se ilustrará el Aporte Didáctico que comprende:

Desarrollo de destrezas: Desarrolla la motricidad gruesa, destreza de trepar, la agilidad, rapidez, fuerza, coordinación, ubicación espacial y temporal, introyección. Desarrolla valores: respeto, colaboración, solidaridad. Adaptaciones: Este juego puede ser adaptado para la escuela desde los 8 años. Se puede utilizar cuerda con nudos. Estrategias en equipo (Analuiza, Lara y Mendoza, 2017, p. 83-84).

Por otra parte, con el juego mestizo la EF se alimenta curricularmente y alimenta el curriculum de las demás áreas contribuyendo con la formación integral porque:

1) Existe un uso creativo del lenguaje oral de manera intensiva y extensiva, al elaborarse y utilizarse códigos específicos (voces) con una gran significación, orientadores, organizadores y base lingüística para el desarrollo de cada juego. Registremos las voces en dos casos:

VENEZUELA: Pisé, descanso: Pisé; perdí; caracol, avión. Libertad, guerra-Policías y ladrones: Bases; matas; tocao; 1,2,3, capturado; libertad; libertad pa todos; ejército y marina, policías y ladrones. Metras: Se han localizado al menos 90 voces, entre las que 
se pueden mencionar: tribilín, círculo, rayo, rayito; raya; sacar; sacado; pega; casó; vale madrina; ya llevo hueca; tosaque; chiripa; topocho; por quien me lleve; cuatro deosuñita; maracucho; todo limpio; nada limpio; jalaito; cariaquito; ful; empujaito; retruque, gano; como te agarre ahí; leva. El cuartillo de larepita: Bases; ya; dame el cuartillo de larepita; que no es aquí que es allá; yo no lo tengo, lo tiene fulano (nombre de otro jugador); se la queda; quedao. Trompo: Pique; quedao; paseo; clavados, chipolas, amapolas; darle totes. El gato y el ratón: Gato; ratón; tocao; ¿quién es?, ¿a quién busca?, está durmiendo, no está, ya salió; se la queda. Volantín, petaca, papagallo: Echale; estrella; ache; trompo; cajón; flochita; culequera; córtalo. Stop-fusilao: Stop; fusilao; quedao; fusilar; llevais uno, dos; se movió; voz no correís así. Cuerdas: Perder; tendrá uno, tendrá dos, tendrá tres...; será rancho, será casa, será quinta (Altuve, 1995).

ECUADOR: Rayuela: avión, gato, días de la semana; gura. Perros y venados-Policías y ladrones: guardias, ladrones; cárcel; salvados; tocados. Las cuatro esquinas: ¿qué hay en la casita que alquilar?, a otro lugar que ésta está ocupá; se queda; se lo queda; pasa a quedarse. Canicas, bolas: bomba, bolas, ñoco, pepo y trulo, culebra; bombardero; bombardear; círculo; tirando; tirada; túnel: triángulo. Trompo; Cushpi: ¿don tá la bola guambrito?; ¿don tá la vida, carajo?; ¡haber pata amarilla!; ¡mil a pucho de tabaco que no pega la bola!; ¡qué no pasa el poste!; iqué no pasa la esquina!; iqué no pega en bola!; éste da como sordo mismo; ¡hoy te hago bailar como cushpe!; ¡te hacen bailar en la uña no! (Becerra, 2011; Ministerio del Deporte).

2) Se desarrolla la expresión corporal con la presencia de gestos, ritmo, escena, poses y movimientos característicos del cuerpo en cada juego. Por ejemplo, todo el juego de la señorita $\mathbf{x}$ transcurre brincando, bailando y cantando: Participantes: Generalmente niñas, también lo jugaban niños. Material: Espacio. Duración: Indefinida. Descripción: Tomados de la mano forman un círculo, una o uno escogido al azar pasa al centro y comienza a desplazarse, brincando, bailando, al son de la canción interpretada por todos y todas "la señorita $X$ (o el señorito $X$ ) va entrando en el baile, que lo baile, que lo baile y si no lo baila la prenda pagará, que la(o) saque, que la(o) saque, salga usted que la(o) quiero ver bailar, bailar, bailar", en este momento el o la participante que baila escoge otro u otra y bailan en el centro del círculo cantando 
colectivamente "Buenos Aires que baile la (el) moza(o), déjenla (o) sola (o), sola (o), solita (o)", inmediatamente el primer bailarín se incorpora al círculo quedando el segundo en el centro. Se repite la canción y todo el proceso descrito (Altuve, 1995).

3) Se cultiva el trabajo manual e intelectual, el conocimiento científico y desarrollo de la capacidad tecnológica combinado con el cultivo del arte, en un proceso que comprende desde diseñar y construir el juguete hasta el acto de jugar. Por ejemplo, el diseño del volantín, papagayo, petaca, cometa es un acto artístico (forma, combinación de colores, etc.) armónicamente articulado con su construcción donde se aplican las leyes aerodinámicas más avanzadas,

...por definición...es un aeroplano atado o sujeto por una cuerda y el vuelo...depende del aire, la construcción y el frenillo, el peso, el balance, el tamaño, la velocidad, estabilidad y presión del viento, la altitud, el terreno, la tensión de la cuerda, la permeabilidad del papel, el tamaño de la cola, la profundidad del arco, la rigidez de la forma: todo afecta el vuelo y deberá ser considerado en el diseño (Calzadilla, 1979, p. 147).

4) Se cultiva una relación armónica con la naturaleza al asumirse como recursos fundamentales las personas y su entorno ecológico, la capacidad creativa para buscar, utilizar, diseñar y elaborar los materiales necesarios sin agredir al medio ambiente.

5) Se perciben relaciones y conceptos matemáticos. Por ejemplo, en las metras, canicas, bolitas, se utilizan rectas, cuadrados, rectángulos, triángulos, circunferencias, etc

6) Se desarrolla otras habilidades, capacidades y destrezas: Pisé, descanso; Rayuela: Equilibrio; precisión; agudeza visual; sentido de orientación; capacidad para retener imágenes, figuras y dimensiones; concentración; sentido del tacto. "Desarrolla la motricidad gruesa, la coordinación viso motora, el equilibrio, puntería, ubicación espacial, precisión, sociabilidad, orden, introyección" (Analuiza, Lara y Mendoza, 2017, p. 87). Libertad, guerra; Perros y venados-Policías y ladrones: Desempeño de roles; agudeza visual y periférica; agilidad. Metras; Canicas, bolas: Resistencia a la fatiga; coordinación; sentido de 
movimiento; agilidad física y mental; agudeza visual y auditiva; visión periférica; reconocimiento táctil. "Desarrollo de la motricidad fina y gruesa, precisión, coordinación, puntería, ubicación espacial con el objeto, creatividad, introyección" (Analuiza, Lara y Mendoza, 2017, p. 89). Trompo; Cushpi: Resistencia a la fatiga; Coordinación, sentido del movimiento, agilidad física y mental; agudeza visual y auditiva, visión periférica, reconocimiento táctil. "Desarrolla precisión, coordinación aculo manual, ubicación en el espacio con el objeto, creatividad, introyección, percepción, mecanización de gestos motores. Desarrolla valores como: el respeto, la colaboración" (Analuiza, Lara y Mendoza, 2017, p. 85).Volantín, papagayo, petaca: Creatividad, destreza manual. Stop, fusilao: Precisión y agudeza visual; agilidad. Siga al jefe: Sentido de movimiento; imitación (Altuve, 1992, p. 87).

\section{Juego Indígena}

Cuadro N.5. Movimientos ejecutados en juegos indígenas previos a la conquista.

\begin{tabular}{|c|c|c|c|}
\hline Juego & Movimiento ejecutado & Nombre común & Nombre técnico \\
\hline $\begin{array}{l}\text { Pelota azteca- } \\
\text { maya. }\end{array}$ & $\begin{array}{l}\text { Hacer pasar la pelota } \\
\text { por cualquiera de los } \\
\text { anillos, manteniéndola } \\
\text { en el aire. Usando } \\
\text { solamente para } \\
\text { golpearla las nalgas, } \\
\text { codos, caderas, muslos } \\
\text { y rodillas. }\end{array}$ & $\begin{array}{l}\text {-Movimiento hacia } \\
\text { arriba con las nalgas. } \\
\text {-Encoger y subir los } \\
\text { brazos. } \\
\text {-Golpear hacia arriba } \\
\text { con las caderas. } \\
\text {-Movimiento hacia } \\
\text { arriba de los muslos. } \\
\text {-Encoger y estirar las } \\
\text { rodillas }\end{array}$ & $\begin{array}{l}\text {-Elevación de la región coxofemoral } \\
\text { (glúteos.) } \\
\text {-Abducción y aducción de miembros } \\
\text { superiores con flexión húmero } \\
\text { antebraquial. } \\
\text {-Movimientos laterales con elevación } \\
\text { de la región coxofemoral (caderas). } \\
\text {-Flexión de la región coxofemoral. } \\
\text {-Flexión y extensión de la región } \\
\text { femorotibial. }\end{array}$ \\
\hline $\begin{array}{l}\text { Pelota } \\
\text { othomaca. }\end{array}$ & $\begin{array}{l}\text { Sacar, rechazar, elevar, } \\
\text { trasladar la pelota } \\
\text { de un equipo a otro } \\
\text { con la cabeza, codos, } \\
\text { hombros, espalda y } \\
\text { nalgas. }\end{array}$ & $\begin{array}{l}\text {-Encoger y subir los } \\
\text { brazos. } \\
\text {-Juntar y separar los } \\
\text { brazos del cuerpo. } \\
\text {-Subir y bajar los } \\
\text { hombros. } \\
\text {-Mover la cabeza a } \\
\text { los lados, adelante } \\
\text { y atrás. } \\
\text {-Movimiento hacia los } \\
\text { lados con las nalgas. }\end{array}$ & $\begin{array}{l}\text {-Abducción y aducción del miembro } \\
\text { superior, con flexión húmero } \\
\text { antebraquial. } \\
\text {--Abducción y aducción de miembros } \\
\text { superiores. } \\
\text {-Elevación y depresión de los } \\
\text { hombros. } \\
\text {-Inclinación lateral (extensión, flexión } \\
\text { e hiperextensión del cuello). } \\
\text {-Flexión, extensión e } \\
\text { hiperextensión del tronco. } \\
\text {-Movimientos laterales (a nivel de la } \\
\text { región coxofemoral). }\end{array}$ \\
\hline
\end{tabular}

Fuente: Altuve, 1995. 
Cuadro N.6. Contenidos y objetivos de educación física de primer año del ciclo diversificado $\left(^{\star}\right)$ venezolano, a desarrollar y alcanzar con juegos indígenas previos a la conquista.

\begin{tabular}{|c|c|c|c|c|c|}
\hline $\begin{array}{l}\text { Objetivo } \\
\text { específico }\end{array}$ & Contenido & Estrategia & $\begin{array}{l}\text { Nombre del } \\
\text { juego }\end{array}$ & $\begin{array}{l}\text { Actividades } \\
\text { del juego }\end{array}$ & Observaciones \\
\hline $\begin{array}{l}\text { 4.- Participar } \\
\text { en juegos o } \\
\text { competencias } \\
\text { deportivas } \\
\text { reglamentadas, } \\
\text { en la } \\
\text { especialidad } \\
\text { seleccionada, } \\
\text { aplicando los } \\
\text { fundamentos } \\
\text { técnicos y } \\
\text { tácticos, } \\
\text { demostrando } \\
\text { adecuada } \\
\text { preparación } \\
\text { física general. }\end{array}$ & $\begin{array}{l}\text { Deporte. } \\
\text { Competencias } \\
\text { reglamentadas. } \\
\text { Fundamentos } \\
\text { técnicos. } \\
\text { Fundamentos } \\
\text { tácticos. } \\
\text { Preparación } \\
\text { física general. }\end{array}$ & $\begin{array}{l}\text { Seleccionar } \\
\text { juegos o } \\
\text { competencias } \\
\text { deportivas que } \\
\text { permitan la } \\
\text { aplicación de } \\
\text { las destrezas } \\
\text { deportivas, que } \\
\text { respondan a las } \\
\text { necesidades e } \\
\text { intereses de los } \\
\text { jugadores. } \\
\text { Explicar a los } \\
\text { alumnos las } \\
\text { características } \\
\text { de cada juego, } \\
\text { en función de } \\
\text { las fuentes } \\
\text { energéticas que } \\
\text { se utilizan y las } \\
\text { capacidades } \\
\text { físicas } \\
\text { involucradas. }\end{array}$ & $\begin{array}{l}\text { Pelota } \\
\text { azteca-maya. } \\
\text { Pelota } \\
\text { othomaca. }\end{array}$ & $\begin{array}{l}\text { Participar } \\
\text { en juegos o } \\
\text { competencias } \\
\text { deportivas, } \\
\text { usando reglas, } \\
\text { técnicas y } \\
\text { tácticas. }\end{array}$ & $\begin{array}{l}\text { El objetivo } \\
\text { puede cumplirse } \\
\text { con los juegos. }\end{array}$ \\
\hline
\end{tabular}

$\left.{ }^{\star}{ }^{\star}\right)$ Cuarto año del bachillerato que tiene una duración de dos años (primero y segundo del ciclo diversificado).

Fuente: Altuve, 1995. 
Cuadro N.7. Contenidos y objetivos de educación física de segundo año del ciclo diversificado venezolano, a desarrollar y alcanzar con juegos indígenas previos a la conquista.

\begin{tabular}{|c|c|c|c|c|c|}
\hline Objetivo & Contenido & Estrategias & $\begin{array}{l}\text { Nombre del } \\
\text { juego }\end{array}$ & $\begin{array}{l}\text { Actividades del } \\
\text { juego }\end{array}$ & Observaciones \\
\hline $\begin{array}{l}\text { 2.- Participar en } \\
\text { la planificación } \\
\text { de una } \\
\text { competencia } \\
\text { del deporte } \\
\text { seleccionado, } \\
\text { que involucre } \\
\text { a alumnos } \\
\text { del plantel, } \\
\text { aplicando los } \\
\text { conocimientos } \\
\text { teóricos } \\
\text { adquiridos. }\end{array}$ & $\begin{array}{l}\text { Planificación } \\
\text { de una } \\
\text { competencia: } \\
\text { objetivos, } \\
\text { comisiones } \\
\text { de trabajo, } \\
\text { recursos. }\end{array}$ & $\begin{array}{l}\text { Realizar la } \\
\text { planificación } \\
\text { de los juegos } \\
\text { pelota azteca- } \\
\text { maya y pelota } \\
\text { othomaca, } \\
\text { en cuatro } \\
\text { sesiones de } \\
\text { clase. }\end{array}$ & $\begin{array}{l}\text { Pelota } \\
\text { azteca-maya. } \\
\text { Pelota } \\
\text { othomaca. }\end{array}$ & $\begin{array}{l}\text { Formación de } \\
\text { ajedrez. } \\
\text { Formación en } \\
\text { columnas. } \\
\text { Coordinación. } \\
\text { Desplazamientos. }\end{array}$ & $\begin{array}{l}\text { El objetivo } \\
\text { puede } \\
\text { cumplirse con } \\
\text { los juegos. }\end{array}$ \\
\hline $\begin{array}{l}\text { 3.- Demostrar } \\
\text { conocimientos } \\
\text { teóricos y } \\
\text { prácticos acerca } \\
\text { del reglamento } \\
\text { del deporte } \\
\text { seleccionado, } \\
\text { en lo referido } \\
\text { al arbitraje de } \\
\text { competencia }\end{array}$ & $\begin{array}{l}\text { Arbitraje } \\
\text { de juego o } \\
\text { juicios de } \\
\text { competencia. }\end{array}$ & $\begin{array}{l}\text { Los alumnos } \\
\text { realizarán los } \\
\text { juegos de la } \\
\text { pelota azteca- } \\
\text { maya y pelota } \\
\text { othomaca en } \\
30 \text { minutos, } \\
\text { donde } \\
\text { podrán } \\
\text { arbitrar } \\
\text { los juegos } \\
\text { cumpliendo } \\
\text { con las } \\
\text { indicaciones. }\end{array}$ & $\begin{array}{l}\text { Pelota } \\
\text { othomaca. } \\
\text { Pelota } \\
\text { azteca-maya. }\end{array}$ & $\begin{array}{l}\text { Rotación. } \\
\text { Formación en } \\
\text { columnas. }\end{array}$ & $\begin{array}{l}\text { El objetivo } \\
\text { puede } \\
\text { cumplirse con } \\
\text { los juegos. }\end{array}$ \\
\hline
\end{tabular}

Fuente: Altuve, 1995.

Se concluye esta parte puntualizando lo siguiente:

1.- La experiencia directa y aplicación del juego latinoamericano puede sintetizarse en:

la I Muestra-Exhibición del Deporte Aborigen existente en América Latina antes de la conquista y colonización europea y I Exhibición y Festival de Juego Latinoamericano (Universidad del Zulia, Maracaibo-Estado Zulia-Venezuela); 
en la actividad escolar y con la comunidad en Escuelas de Fe y Alegría en el Estado Zulia, entre los años 19901997; el Festival del Juego Latinoamericano (Alcaldía de Maracaibo, 1994); Congreso Panamericano de Educación Física, Deporte y Recreación (Lima 1995); Congreso Latinoamericano de Deporte Para Todos (Brasil, 1996) (Altuve, 1997, p. XV).

2.- Resulta conveniente precisar que no existe una manera única de incorporar el juego latinoamericano en el desarrollo de contenidos y cumplimiento de objetivos parcial y/o totalmente, en el curriculum de educación física. Existen muchas formas, él y la docente tendrá que determinar la que va a utilizar considerando la situación concreta, teniendo como referencia la nueva educación física por construir, colectiva y creativamente, donde los profesores y profesoras están llamados a desempeñar un importante papel.

3.- Una vez consultados los objetivos del área de Educación Física en los niveles del sistema educativo de Ecuador, creemos que es posible incorporar el juego latinoamericano de alguna manera con su cumplimiento o logro; obviamente, será un proceso colectivo y de debate. Particularmente, en: Subnivel de Preparatoria de Educación General Básica: $1.1 ; 1.2 ; 1.3 ; 1.4 ; 1.6 ; 1.7$ y 1.8 . Subnivel Elemental de Educación General Básica: $2.1 ; 2.2 ; 2.3 ; 2.4 ; 2.5 ; 2.7 ; 2.8$ y 2.9 . Subnivel Medio de Educación General Básica: $3.1 ; 3.2 ; 3.4 ; 3.5 ; 3.7 ; 3.8$ y 3.9. Subnivel Superior de Educación General Básica: 4.1; 4.3; 4.4; 4.5; 4.7; 4.8 y 4.9. Bachillerato General Unificado: $1 ; 2,3 ; 4 ; 7 ; 8$ y 9 (Ministerio de Educación, 2018).

\section{Conclusiones}

1.- El juego latinoamericano como parte del entorno impregna y marca de alguna manera la corporeidad de los y las estudiantes, bien sea por su práctica y/o a través de la influencia familiar. Forma parte del movimiento corporal que el niño-niña y jóvenes llevan a la escuela.

2.- La incorporación del juego latinoamericano a la dinámica de la clase de $E F$, contribuye a valorar nuestras raíces y construir nuestra identidad nacional y latinoamericana. 
3.- La intensiva y extensiva dimensión formativa en términos físicos del juego latinoamericano, fundamenta su incorporación al desarrollo regular, ordinario, de la clase de $E F$, justifica su presencia en el desarrollo del currículum.

4.- Adicionalmente, la dinámica del juego latinoamericano comprende el cultivo y desarrollo del lenguaje, el arte, el conocimiento científico y tecnológico, las matemáticas, etc., alimentando el curriculum de las otras áreas contribuyendo con la formación integral. Creando posibilidades inmensas de comunicación-intercambio entre la EF y las demás áreas.

5.- La incorporación del juego latinoamericano a la EF permite a los y las docentes: disponer de una poderosa herramienta (junto a otras), a los efectos de desarrollar los contenidos del programa establecido, así como desarrollar habilidades y destrezas que exceden el marco programático; crear un puente de comunicación e intercambio con las demás áreas del curriculum; desarrollar una productiva y placentera clase de EF utilizando recursos bastante accesibles en cuanto a costo. Obviamente, su inclusión en las diferentes partes de la clase de EF y en el desarrollo parcial y/o total de los contenidos, dependerá del tipo de contenido programático, de la situación y desarrollo particular y del papel de profesores y profesoras.

6.- Es imperativo continuar la investigación, profundizar y sistematizar el juego latinoamericano en Ecuador, Venezuela y el resto de América Latina. Simultáneamente con el adelanto de un proceso de sistematización de experiencias, sobre el resultado de la incorporación del juego latinoamericano a la clase de EF.

\section{Bibliografía}

Altuve, Eloy. (1992). Educación, Educación Física y Juegos Tradicionales. Maracaibo-Venezuela: Ediciones Astrodata. Pp.128.

Altuve, Eloy. (1995). Educación Física, Deporte y Recreación. Colección Procesos Educativos. N.9. Caracas-Venezuela: Fe y Alegría. Pp. 48 Altuve, Eloy. (1997). Juego, Historia, Deporte y Sociedad en América 
Latina. Centro Experimental de Estudios Latinoamericanos, Universidad del Zulia. Maracaibo-Venezuela: EdiLUZ. Pp.150.

Altuve, Eloy (2000). Deporte, globalización e integración en América Latina. Centro Experimental de Estudios Latinoamericanos, Universidad del Zulia. Maracaibo-Venezuela: EdiLUZ. Pp.80.

Altuve Mejía, Eloy. (2009). Juego y revolución en América Latina. Revista de História do Esporte, Volumen 2, N. 2. Programa de Postgrado en Historia Comparada/IFCS/Universidad Federal de Río de Janeiro-Brasil. Pp. 1-24.

Analuiza A., Edison (Tarpuk); Lara Chalá, Lilia y Mendoza Yépez, Marlene Margarita. Los Juegos Populares y su aporte didáctico en las clases de Educación Física. EmásF, Revista Digital de Educación Física. Año 8, Numero 44 (enero-febrero de 2017). En https:// emasf.webcindario.com/Los juegos populares y su aporte didactico a las clases de EF.pdf. Consultada el 09-10-18.

Becerra C., Narcisa E. Los Juegos Tradicionales en el desarrollo motriz de niños/as del primer año de Educación Básica de la ciudad de Quito, sector CHillogallo (29-03-2011). En http://www.dspace.uce. edu.ec/bitstream/25000/214/1/T-UCE-0010-35.pdf. Consultada el 05-10-18.

Calzadilla, J. (1979). La aerodinámica de los papagayos. En: Los Navegantes de Colores. Caracas-Venezuela: La Huella-Tecnicolor. Pp.159.

Gumilla, José. (1968). Tribus Indígenas del Orinoco. Caracas-Venezuela: Ediciones Culturales INCE. Pp.84.

Hernández, Santos. (1876). Juegos de los Niños en las Escuelas y Liceos. Madrid-España: Casa Editorial Saturnino Calleja Fernández.

López Cantos, Ángel. (1992). Juegos, Fiestas y Diversiones. Madrid: Editorial MAPFRE. Pp.332.

Martínez, Catherine. 15 Juegos Tradicionales del Ecuador de Niños y Adolescentes. En https://www.lifeder.com/juegos-tradicionalesecuador/. Consultada el 09-10-18.

Ministerio del Deporte, Ecuador. Juegos y deportes autóctonos del Ecuador. (2010).En http://aplicativos.deporte.gob.ec/ 
investigacion/libros/JUEGOS AUTOCTONOS ECUADOR 2010. pdf-. Consultada el 05-10-18.

Ministerio de Educación, Ecuador. Currículo de EF en EGB y BGU. 08-2016. En https://educacion.gob.ec/wp-content/uploads/ downloads/2016/08/EF-completo.pdf. Consultada el 08-10-2018.

Moreno Palos, Cristóbal (1974). Juegos y Deportes Tradicionales en España. Madrid- Alianza Editorial: Consejo Superior de Deportes. Pp.432.

Parra B., José F. El rescate de los Juegos Populares ecuatorianos y su aplicación en la animación turística. Universidad de Cuenca. (2010). En http://dspace.ucuenca.edu.ec/bitstream/123456789/1726/1/ tur10.pdf. Consultada el 05-10-18.

Plath, Orestes. (1986) Aproximación Histórico-Folklórica de los Juegos en Chile. Ritos, mitos y tradiciones. Santiago de Chile-Chile: Editorial Nascimento. Pp.455.

Rodríguez Marín, Francisco. Juegos Infantiles del siglo XVI. Tomo XVIII, Cuaderno LXXXIX-Octubre 1931, Tomo XVIII, Cuaderno XCDiciembre 1931, Tomo XIX, Cuaderno XCI-Febrero 1932.

Vidart, Daniel. (1986). Filosofía Ambiental. Bogotá, Colombia: Editorial Nueva América. 